\title{
A New Algorithm for Two-terminal Fault Location Based on Distributed Parameter Line Model
}

\author{
Fan Rong Wang 1, 2,a, Hong Zhou ${ }^{1, b^{*}}$ \\ ${ }^{1}$ Department of Automation, Wuhan University, Wuhan,China \\ ${ }^{2}$ School of Electrical \& Electronic Engineering,Hubei University of Technology, Wuhan,China \\ a wfr@mail.hbut.edu.cn, bhzhouwuhee@263.net
}

Keywords: Failure analysis; Ranging function; Distributed parameter; Transmission line

\begin{abstract}
This paper presents a new algorithm for two-terminal fault location in transmission line. It creates a fault-based information ranging function. According to the characteristic of the function, it analyzes the trajectory of function vector and finds the failure point the by recursive function. It uses PSCAD and MATLAB to simulate and prove its correction.
\end{abstract}

\section{Introduction}

Under the conditions of transmission lines system parameters known, the voltage and current of both line ends are functions of fault distance when a fault occurs on one point of transmission line.Failure analysis method is a common fault location algorithm and it an be achieved with existing fault recorder purposes ranging. It Establishes fault location equations according to system parameters and electrical quantities of measuring points, then calculates the distance between failure point and measuring points.

There are two types of failure analysis used for fault location. Single-ended fault location[1-10] uses only one end of the line current and voltage information to determine the fault distance.It does not need the channel to transmit opposite side data, so it is not limited by communication technology. Fault location algorithm using single-ended data can be divided into three categories.The first is the method for solving differential equations. The second uses power frequency electrical quantities to locate fault position.The third finds the fault location according to the characteristics of the voltage distribution along the line under fault conditions.Double-ended fault location[11-17] has sufficient or redundant location equations. It may achieve precise fault location because it can eliminate measuring error affected by transition resistance and other factors.

This paper presents a new double-ended locating algorithm which is based on distributed parameter line model.The method is to create a fault-based information ranging function, and to calculate ranging by a characteristic of ranging function up to the minimum when the independent variables is fault distance by trajectory of function vector.

\section{Algorithm principle}

Assuming the transmission lines is uniform and its parameters are constant,we use distributed parameter line mode shown as figure 1.

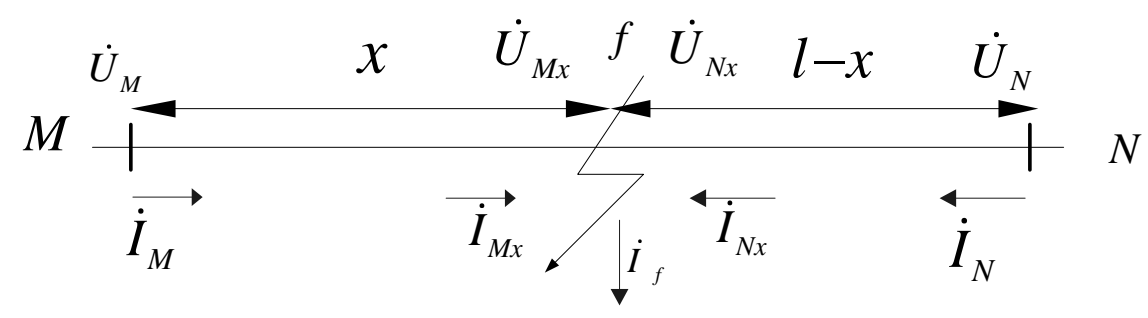

Figure. 1 Double-end fault schematic 
In Fig. $1, \dot{U}_{m} 、 \dot{I}_{m}$ for the voltage and current measurement obtained for M terminal; $\dot{U}_{\mathrm{n}} 、 \dot{I}_{\mathrm{n}}$ for the voltage and current measurement obtained for $\mathrm{N}$ terminal; $l$ for the total length of the line; $\mathrm{x}$ for the $\mathrm{X}$ end to the point of failure F distance; $\dot{I}_{F}$ for the short circuit current fault point. Due to long-wave equation of electrical quantity at $\mathrm{M}$ and $\mathrm{N}$ terminal, two equations are established,in

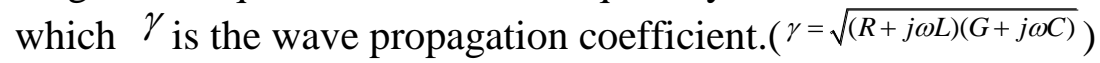

$$
\begin{aligned}
& \left\{\begin{array}{l}
\mathcal{L}_{M x}^{\&}=U_{M}^{\&} \cosh \gamma x-\mathbb{K}_{M}^{\&} Z \sinh \gamma x \\
\underset{M x}{\mathbb{E}}=-\mathcal{L}_{M}^{\&} \sinh \gamma x / Z+\mathbb{M}_{M}^{\&} \cosh \gamma x
\end{array}\right.
\end{aligned}
$$

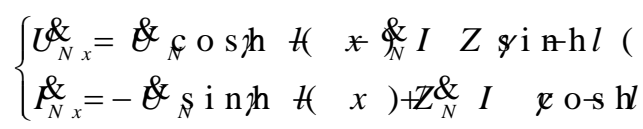

Due to (1) and (2):

$$
\begin{gathered}
\left|\mathcal{U}_{M x}^{\&}-U_{N x}^{\&}\right|=\left|U_{M}^{\&} \cosh \gamma x-I_{M}^{\&} Z \sinh \gamma x-U_{N}^{\&} \cosh \gamma(l-x)+I_{N}^{\&} Z \sinh \gamma(l-x)\right| \\
\left|H_{M x}^{\&}+I_{N x}^{\&}\right|=\left|-U_{M}^{\&} \sinh \gamma x / Z+H_{M}^{\&} \cosh \gamma x-U_{N}^{\&} \sinh \gamma(l-x) / Z+H_{N}^{\&} \cosh \gamma(l-x)\right|
\end{gathered}
$$

creating ranging function $F(x)$ :

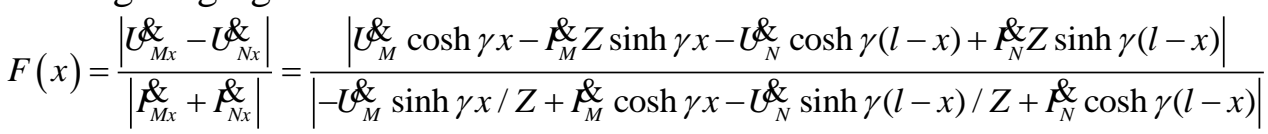

Due to hyperbolic function definition $\left(\sinh \gamma x=\frac{e^{\gamma x}-e^{-\gamma x}}{2}, \cosh \gamma x=\frac{e^{\gamma x}+e^{-\gamma x}}{2}\right)$,Equation 5 becomes Equation 6.

$$
\begin{gathered}
F(x)=\frac{\left|e^{2 \gamma x}(-a)+b\right|}{\left|e^{2 \gamma x} \times a+b\right|} \times Z \\
a=-\dot{U}_{M}+\dot{I}_{M} Z+\dot{U}_{N} e^{-\gamma l}+\dot{I}_{N} Z e^{-\gamma l}, b=\dot{U}_{M}+\dot{I}_{M} Z-\dot{U}_{N} e^{\gamma l}+\dot{I}_{N} Z e^{\gamma l} 。
\end{gathered}
$$

The fault point voltage calculated from the $\mathrm{M}$ end equals to which calculated from the $\mathrm{N}$ end,

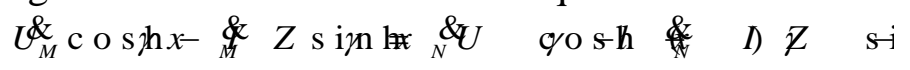

Due to hyperbolic function definition, the following equation is created.

$$
-\dot{U}_{M}+\dot{I}_{M} Z+\dot{U}_{N} e^{-\gamma l}+\dot{I}_{N} Z e^{-\gamma l}=e^{2 \gamma x} \times\left(\dot{U}_{M}+\dot{I}_{M} Z-\dot{U}_{N} e^{\gamma l}+\dot{I}_{N} Z e^{\gamma l}\right)
$$

It means $a=e^{2 \gamma x} \times b$ 。So equation 8 is created.

$$
|a|=|b|
$$

Figure 2 shows a vector diagram which represents equation 6.

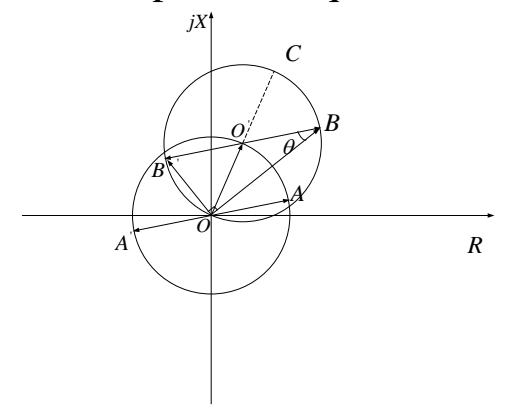

Figure. 2 Vector Schematic

In figure $2, a=\overrightarrow{O A}, b=\overrightarrow{O O^{\prime}}, \quad e^{2 \gamma x} \cdot a$ is a set of rounded edges with center $\mathrm{O}$ and radius $\left|O O^{\prime}\right|$. $\overrightarrow{O B}=\overrightarrow{O A}+\overrightarrow{O O^{\prime}}, \overrightarrow{O B^{\prime}}=\overrightarrow{O A^{\prime}}+\overrightarrow{O O^{\prime}}$, the round with center $O^{\prime}$ and radius $\left|O O^{\prime}\right|$ shows the 
trajectory of point $B, B^{\prime}$. Because $\overrightarrow{O A}$ and $\overrightarrow{O A}$ is in the opposite direction, it is easy to get $\angle B^{\prime} O B=\frac{\pi}{2}$ by the geometric relationship , and equation 6 can be replaced by equation 9.

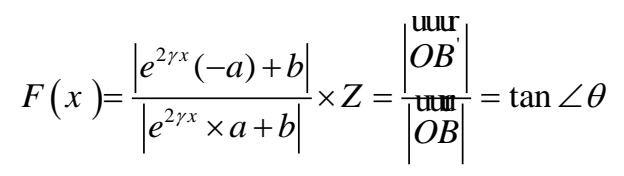

Points $B, B^{\prime}$ respectively walk along the arc $B C B^{\prime} B^{\prime} A B$ counterclockwise with the same speed, $\left.\left.|O B|\right|^{\text {uum }} O B^{\prime}\right|_{\text {also change }} ^{\text {uur }}$ As B gradually moves to the $\mathrm{C}$ point, $\quad|O B|_{\text {in }}^{\text {uum }}$ uur this time point $B^{\prime}$ moves to point $\mathrm{O},{ }^{\left|O B^{\prime}\right|}$ gradually reduces to the minimum.。. And then $|O B|$

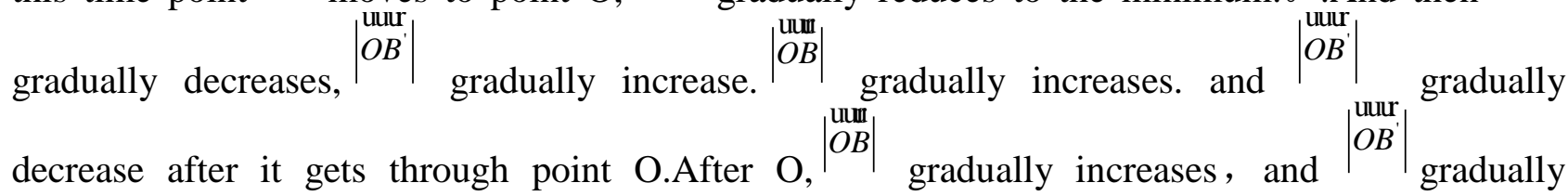
decreases. so $\tan \angle \theta$ reaches the minimum of 0 when $\mathrm{B}$ moves to $\mathrm{C}$. The following equations can be obtained.

$$
\begin{gathered}
\left\{\begin{array}{l}
\overrightarrow{O A} \cdot e^{2 \gamma x}=\overrightarrow{O O} \\
\overrightarrow{O A} \cdot e^{2 \gamma x}=-1 \cdot \overrightarrow{O O}
\end{array}\right. \\
\left(-\dot{U}_{M}+\dot{I}_{M} Z+\dot{U}_{N} e^{-\gamma l}+\dot{I}_{N} Z e^{-\gamma l}\right) e^{2 \gamma x}=\dot{U}_{M}+\dot{I}_{M} Z-\dot{U}_{N} e^{\gamma l}+\dot{I}_{N} Z e^{\gamma l}
\end{gathered}
$$

Due to (7) and (8),(11) is true and $F(x)$ is the minimal when the value of $\mathrm{X}$ is the distance between the point of failure and the end $M$.

In three-phase systems, due to the existence of incomplete transposition and coupling phenomenon between the phase line, the measurement accuracy of algorithm will be affected. Karrenbauer transformation used in this paper to decouple a three-phase electrical. It transforms Phase space into the module space and uses modular space electric quantities to calculate. It take a phrase ground fault for example to analyze the Principle.

$$
\begin{gathered}
{\left[\begin{array}{l}
\dot{U}_{M \alpha} \\
\dot{U}_{M \beta} \\
\dot{U}_{M 0}
\end{array}\right]=\frac{1}{3}\left[\begin{array}{ccc}
1 & -1 & 0 \\
1 & 0 & -1 \\
1 & 1 & 1
\end{array}\right]\left[\begin{array}{l}
\dot{U}_{M A} \\
\dot{U}_{M B} \\
\dot{U}_{M C}
\end{array}\right]} \\
{\left[\begin{array}{c}
\dot{I}_{M \alpha} \\
\dot{I}_{M \beta} \\
\dot{I}_{M 0}
\end{array}\right]=\frac{1}{3}\left[\begin{array}{ccc}
1 & -1 & 0 \\
1 & 0 & -1 \\
1 & 1 & 1
\end{array}\right]\left[\begin{array}{c}
\dot{I}_{M A} \\
\dot{I}_{M B} \\
\dot{I}_{M C}
\end{array}\right]}
\end{gathered}
$$

Inserting equation 12 and 13 to equation 1 ,equation 14 is obtained.

$$
\left\{\begin{array}{l}
U_{M x}^{\&}=U_{M}^{\&} \cosh \gamma^{i} x-I_{M}^{\&} Z^{i} \sinh \gamma^{i} x \\
F_{M x}^{\&}=-U_{M}^{\&} \sinh \gamma^{i} x / Z^{i}+L_{M}^{\&} \cosh \gamma^{i} x
\end{array}\right.
$$

Among $i=\left\{\begin{array}{lll}\alpha & \beta & 0\end{array}\right\}$ represents the modulus.Similarly, the $\mathrm{N}$-terminal electrical modulus can also be calculated. Together with equation 6 ,equation 15 can be obtained.

$$
F^{i}(x)=\frac{\left|e^{2 \gamma^{i} x}\left(-a^{i}\right)+b^{i}\right|}{\left|e^{2 \gamma^{i} x} \times a^{i}+b^{i}\right|} \times Z^{i}
$$




$$
a^{i}=-\dot{U}_{M}^{i}+\dot{I}_{M}^{i} Z^{i}+\dot{U}_{N}^{i} e^{-\gamma^{i} l}+\dot{I}_{N}^{i} Z^{i} e^{-\gamma^{i} l}, b^{i}=\dot{U}_{M}^{i}+\dot{I}_{M}^{i} Z^{i}-\dot{U}_{N}^{i} e^{\gamma^{i} l}+\dot{I}_{N}^{i} Z^{i} e^{\gamma^{i} l} \quad 。 \quad F^{i}(x) \quad \text { gradually }
$$

reduces to minimum when $\mathrm{x}$ moves from the $\mathrm{M}$ terminal to the point of failure. $F^{i}(x)$ gradually increases when $\mathrm{X}$ moves from the point of failure to the $\mathrm{N}$ terminal.According to this characteristic it measures fault distance.

\section{Algorithm simulation}

In order to verify the correctness of the algorithm, this paper uses the distributed parameter line model to build EMTDC transmission line model with a total length of $600 \mathrm{kM}$, as shown in Fig.3

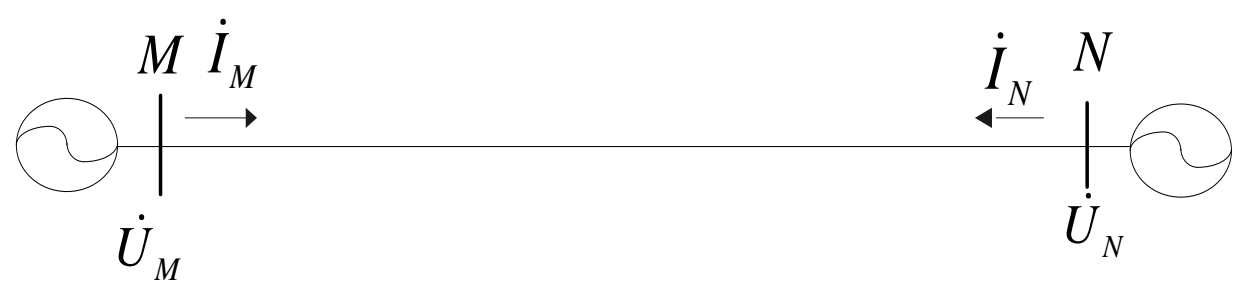

Figure. 3 System simulation model

\section{Some Parameters:}

$r_{1}=0.02083 \Omega / \mathrm{km} \quad ; \quad l_{1}=0.8948 \mathrm{mH} / \mathrm{km} \quad ; \quad C_{1}=0.0129 \mu \mathrm{F} / \mathrm{km} \quad ; \quad r_{0}=0.1148 \Omega / \mathrm{km} \quad ;$

$l_{0}=2.2886 \mathrm{mH} / \mathrm{km} \quad ; \quad C_{0}=0.0523 \mu \mathrm{F} / \mathrm{km} \quad ; \quad E_{M}=1.05 \mathrm{p} . u . \angle 0^{0} \quad ; \quad R_{M 1}=1.0515 \Omega \quad ;$

$L_{M 1}=0.13743 H ; R_{M 0}=0.6 \Omega ; L_{M 0}=0.0926 H ;$

Fault model is simulated by EMTDC and data is Processed by MATLAB.Sampling Frequency is set of $4 \mathrm{KHZ}$, and total track length of line is divided into 10 divisions. Search step size is $0.6 \mathrm{~km}$. Differential full-wave Fourier algorithm is used to filter.Simulation time is set of $0.22 \mathrm{~s}$, ground fault is found when it is at time of $0.12 \mathrm{~s}$, and fault is finished when it is at time of $0.18 \mathrm{~s}$. Figure 4 shows the simulation diagram of A phase ground fault in $83 \mathrm{kM}$ with different transition resistance.
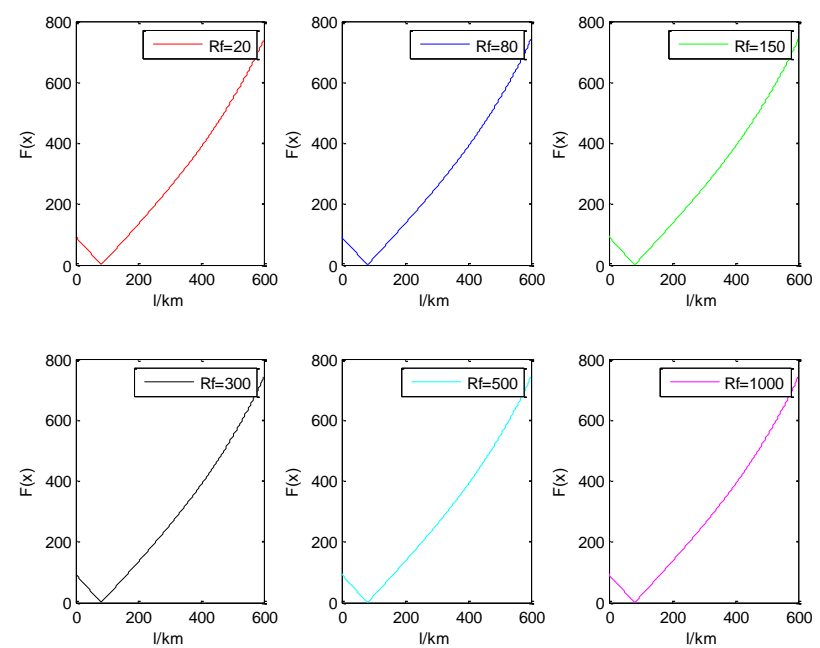

Figure. $4 \quad F(x)$ characteristic of A phase ground at $83 \mathrm{~km}$

Most Factors that affect the ranging accuracy are changed.The ranging effect of this method should be considered. 
Table 1 Effect of grounding resistance and fault location on AG fault location results

\begin{tabular}{|c|c|c|c|c|c|l|l|l|}
\hline Fault & \multicolumn{2}{|c|}{15} & \multicolumn{2}{c|}{35} & \multicolumn{2}{c|}{83} & \multicolumn{2}{c|}{300} \\
\cline { 2 - 9 } $\begin{array}{l}\text { distance } \\
\text { Transition } \\
\text { resistance/ } \Omega\end{array}$ & $\begin{array}{c}\text { Measurin } \\
\text { g distance } \\
/ \mathrm{km}\end{array}$ & $\begin{array}{l}\text { Error } \\
/ \mathrm{km}\end{array}$ & $\begin{array}{c}\text { Measurin } \\
\text { g distance } \\
/ \mathrm{km}\end{array}$ & $\begin{array}{l}\text { Error } \\
/ \mathrm{km}\end{array}$ & $\begin{array}{c}\text { Measurin } \\
\mathrm{g} \text { distance } \\
/ \mathrm{km}\end{array}$ & $\begin{array}{l}\text { Error } \\
/ \mathrm{km}\end{array}$ & $\begin{array}{l}\text { Measuring } \\
\text { distance } \\
/ \mathrm{k} \mathrm{m}\end{array}$ & $\begin{array}{l}\text { Error } \\
/ \mathrm{km}\end{array}$ \\
\hline 20 & 14.98 & 0.02 & 35.23 & 0.23 & 82.79 & 0.21 & 299.86 & 0.14 \\
\hline 80 & 15.08 & 0.08 & 384 & 0.16 & 83.12 & 0.12 & 299.54 & 0.46 \\
\hline 100 & 14.78 & 0.22 & 388 & 0.12 & 83.05 & 0.05 & 299.75 & 0.23 \\
\hline 300 & 14.97 & 0.03 & 384 & 0.16 & 83.15 & 0.15 & 300.24 & 0.24 \\
\hline 500 & 14.85 & 0.15 & 365 & 0.35 & 83.54 & 0.46 & 300.35 & 0.35 \\
\hline
\end{tabular}

Table 2 results of different faults types (Transition resistance for $20 \Omega$ )

\begin{tabular}{|c|c|c|c|c|c|c|c|l|}
\hline Fault distance & \multicolumn{2}{|c|}{15} & \multicolumn{2}{c|}{35} & \multicolumn{2}{c|}{83} & \multicolumn{2}{c|}{300} \\
\cline { 2 - 9 } & $\begin{array}{c}\text { Measurin } \\
\text { g distance } \\
/ \mathrm{km}\end{array}$ & $\begin{array}{c}\text { Error } \\
/ \mathrm{km}\end{array}$ & $\begin{array}{c}\text { Measurin } \\
\text { g distance } \\
/ \mathrm{km}\end{array}$ & $\begin{array}{c}\text { Error } \\
/ \mathrm{km}\end{array}$ & $\begin{array}{c}\text { Measurin } \\
\mathrm{g} \text { distance } \\
/ \mathrm{km}\end{array}$ & $\begin{array}{c}\text { Error } \\
/ \mathrm{km}\end{array}$ & $\begin{array}{c}\text { Measuring } \\
\text { distance } \\
/ \mathrm{km}\end{array}$ & $\begin{array}{l}\text { Error } \\
/ \mathrm{km}\end{array}$ \\
\hline $\mathrm{AG}$ & 14.98 & 0.02 & 35.23 & 0.23 & 82.79 & 0.21 & 299.86 & 0.14 \\
\hline $\mathrm{BC}$ & 14.91 & 0.09 & 35.21 & 0.21 & 83.43 & 0.43 & 300.09 & 0.09 \\
\hline $\mathrm{BCG}$ & 15.11 & 0.11 & 34.57 & 0.43 & 83.12 & 0.12 & 299.89 & 0.11 \\
\hline $\mathrm{ABC}$ & 14.99 & 0.01 & 35.05 & 0.05 & 83.18 & 0.18 & 299.23 & 0.77 \\
\hline
\end{tabular}

Table 3 AG fault location results of different sampling rates (Transition resistance for $20 \Omega$ )

\begin{tabular}{|c|c|c|c|c|c|c|c|c|}
\hline \multirow{2}{*}{$\begin{array}{l}\text { Fault distance } \\
/ \mathrm{km} \\
\text { Sampling } \\
\text { number/cycle }\end{array}$} & \multicolumn{2}{|c|}{15} & \multicolumn{2}{|c|}{35} & \multicolumn{2}{|c|}{83} & \multicolumn{2}{|c|}{300} \\
\hline & $\begin{array}{c}\text { Measurin } \\
\text { g distance } \\
\text { / k m }\end{array}$ & $\begin{array}{l}\text { Error } \\
/ \mathrm{km}\end{array}$ & $\begin{array}{c}\text { Measurin } \\
\text { g distance } \\
\text { / k m }\end{array}$ & $\begin{array}{r}\text { Error } \\
/ \mathrm{km}\end{array}$ & $\begin{array}{l}\text { Measurin } \\
\text { g distance } \\
\text { / } \mathrm{km}\end{array}$ & $\begin{array}{l}\text { Error } \\
/ \mathrm{km}\end{array}$ & $\begin{array}{c}\text { Measuring } \\
\text { distance } \\
\text { / km }\end{array}$ & $\begin{array}{l}\text { Error } \\
/ \mathrm{km}\end{array}$ \\
\hline 80 & 14.98 & 0.02 & 35.23 & 0.23 & 82.79 & 0.21 & 299.86 & 0.14 \\
\hline 40 & 14.34 & 0.66 & 33.92 & 1.08 & 81.79 & 1.21 & 296.36 & 3.64 \\
\hline 20 & 16.22 & 1.22 & 33.56 & 1.44 & 84.51 & 1.51 & 306.35 & 6.35 \\
\hline 10 & 11.46 & 3.54 & 38.79 & 3.79 & 89.35 & 6.35 & 293.34 & 6.66 \\
\hline
\end{tabular}

Table 1 and Table 2 show that the algorithm is largely unaffected by the fault location, size of transition resistance and type of failure transition resistance. The high-impedance grounding can still get a more accurate measurement results. Table 3 shows that the algorithm depends on the size of sample rate.Sampling frequency is higher and the measurement is higher,and vice-verse, it may not meet the engineering needs.

\section{Discussion}

According to the simulation results,measuring accuracy of algorithm satisfies engineering's demands. There are factors affect the accuracy of the algorithm. 
Sampling Frequency. Owing to the analysis of simulation results,sampling frequency is higher and the measurement is harder to be affected by transition resistance.The algorithm is based on the frequency to achieve fault location.It is easy to implement because locating hardware requirements are not high while Traveling wave fault location needs high sampling frequency.

Filtering effect. When unbalanced fault occurs in AC system,it will generate a lot of high harmonics and decaying DC component.If filtering is not well proceeded,it will have a huge effect on the measuring electrical quantity , and eventually lead distance function $\mathrm{F}(\mathrm{x})$ characteristic to shift. Filtering effect will directly affect the size of measuring error. This paper uses a differential full-wave Fourier algorithm, and differential filtering and FIR low-pass filtering may also be used.

System Parameters. Their size are affected by many factors, such as, weather, humidity ,various interference signals and the wire's surface conditions, and so on. This paper does not take into account changes in parameters, but this problem will be solved in the subsequent study by online calculated parameters.

Selection of e and $\mathrm{n}$. A large number of simulation results display that the size of threshold value e are lower, the ranging accuracy is higher,but the computing time is even more.Generally if fault location does not require timely output,the smaller e are appropriate. But in fact, the e may be obtained by the location tolerance because the former is a function of the latter. While the size of equal interval $n$ needs to select the appropriate value because the number of calculations is is a function of the location tolerance.So,if the location tolerance is set,the $\mathrm{n}$ and $\mathrm{e}$ is determined.

\section{Conclusion}

This paper presents a double-ended locating algorithm that is based on distributed parameter line model.The transmission line model of the distributed capacitance currents is considered.The measured distance only needs double-ended electrical quantity.A large number of simulation results display that this algorithm is not affected by transition resistance, system operating mode, fault type and fault distance. High-impedance grounding can still get a more accurate measurement results.The algorithm is based on power frequency and without excessive sampling rate.Increasing the sampling rate can reduce ranging error on the economic conditions. It satisfies location requirements and work demands, and it has high application prospect.

\section{References}

[1] Djuric M B,Terzija V V.A new approach to the arcing faults detection for fast auto-re-closure in transmission systems[J].Power Delivery,IEEE Transactions on,1995,10(4):1793-1798.

[2] Djuric M B,Radojevic Z M,Terzija V V.Time domain solution of faults distance estimation and arcing faults detection on overhead lines[J]. Power Delivery,IEEE Transactions on, 1999, 14(1):60-67.

[3] Takagi T,Yamakoshi Y,Baba J,et al.A New Algorithm of an Accurate Fault Location for EHV/UHV Transmission Lines:Part I-Fourier Transformation Method[J].Power Apparatus and Systems,IEEE Transactions on,1981,PAS-100(3):1316-1323.

[4] Takagi T,Yamakoshi Y,Baba J,et al.A New Algorithm of an Accurate Fault Location for EHV/UHV Transmission Lines:Part II-Laplace Transform Method[J].Power Apparatus and Systems,IEEE Transactions on,1982,PAS-101(3):564-573.

[5] Kawady T, Stenzel J. A practical fault location approach for double circuit transmission lines using single end data[J]. IEEE Trans on Power Delivery, 2003, 18(4): 1166-1173.

[6] Takagi T, Yamakoshi Y, Yamaura M, et al. Development of a new type fault locator using the one-terminal voltage and current data[J]. 1982, V PAS-101(N 8): 2892-2898.

[7] HA Heng-xu, ZHANG Bao-hui, Lü Zhi-lai. A novel principle of single-ended line fault location technique for EHV transmission system[J]. Proceedings of the CSEE, 2003, 23(2): 
$42-45$.

[8] SUONAN Jia-le, QI Jun, CHEN Fu-feng, et al. An accurate fault location algorithm for transmission lines based on R-L model parameter identification[J]. Proceedings of the CSEE, 2004, 24(12): 119-125.

[9] KANG Xiao-ning, SUONAN Jia-le. Frequency domain method of fault location based on parameter identification-using one terminal data[J]. Proceedings of the CSEE, 2005, 25(2): $22-27$.

[10] YANG Cheng, SUONAN Jia-le, LI Ya-li. Study on the fault location algorithm based on R-L model for transmission lines with single-pole reclosure[J]. Automation of Electric Power Systems, 2010, 34(10): 71-75.

[11] Wailar D L,Elangovan S,Liew A C.Fault impedance estimation algorithms for digital distance relaying[J].Power Delivery,IEEE Transactions on,1994,9(3):1375-1383.

[12] JIANG Chun-fang, WANG Ke-ying. Unsynchronous two-terminal fault location algorithm based on line parameter estimation[J]. Relay, 2008, 36(1): 1-4.

[13] Sadeh J, Hadjsaid N, Ranjbar A M, et al. Accurate fault location algorithm for series compensated transmission lines[J]. IEEE Trans on Power Delivery, 2000, 15(3): 1027-1033.

[14] ZHANG Qing-chao, WANG Ying-qiu, SONG Wen-nan, et al. Fault location of transmission line for phase to earth fault based on one terminal voltage and current data[J]. Journal of Tianjin University, 1999, 32(3): 333-336.

[15] CHEN Zheng, SU Jin-xi, WU Xin-rong, et al. Fault location algorithm for high voltage transmission line based on distributed parameter[J]. Power System Technology, 2000, 24(11): 31-33.

[16] LIU Wei, CHEN Hao. A new fault location algorithm for hybrid transmission line based on distributed parameter model[J]. Power System Protection and Control, 2009, 37(24): 76-80.

[17] ZHOU Dong-hua, XI Yu-geng, ZHANG Zhong-jun. Suboptimal fading extended Kalman filtering for nonlinear systems[J]. Control and Decision, 1990, 5(5): 1-6. 